factors influencing colour change were not brought out clearly: background response mediated by the intermediate lobe of the pituitary, response to stress mediated by the autonomic nervous system and adrenal gland and direct response of the chromatophores to temperature. I remain uncertain as to whether Agama agama shows a background response.

I like to think that those interested in animal behaviour will feel that lizards offer a splendid and almost untapped field of study. We can observe almost every phase in the life of a diurnal lizard; some of them seem to thrive as commensals of man. The fact that they, like us, are eye-minded animals makes it easier for us to appreciate much that is important in the life of such lizards. This book should be used by every school in Africa; indeed, it furnishes an argument for the teaching of biology in every school in Africa. I would like further to commend the book to every biology teacher in those warm countries in which lizards abound. Your common lizards will certainly differ from Agama agama, but Dr. Harris's book will give you a wealth of suggestions as to the kind of studies that can be made.

GaRTH UNDERWOOD to the inclusion of several pages which can surely contain nothing but gratuitous information for most readers. Is this the type of book to which even a student would turn for an account of the tricarboxylic cycle or the $\beta$-oxidation of fatty acids? There is also a certain amount of overlap between some contributions, this being particularly evident in the endocrine field. The control of blood-glucose level is considered in a wide-ranging article on amphibian metabolism (G. W. Brown) and the hypothalamic control of pituitary secretion in a thoughtful section on amphibian metamorphosis (W. Etkin). Both these subjects are at least partially covered by A. Gorbman in the chapter on amphibian endocrinology, yet the important field of reproductive endocrinology is only given passing mention as one which has attracted the attention of many investigators.

The text is adequately illustrated, reasonably free from typographical errors and, despite the above strictures, the book is a valuable addition to the literature which should supplement Noble's earlier classic and be welcomed by all who wish to learn of the amphibian way of life.

$$
\text { C. L. Sмrтh }
$$

\section{AMPHIBIAN PHYSIOLOGY}

\section{Physiology of the Amphibia}

Edited by John A. Moore. Pp. xii +654 . (New York and London: Academic Press, 1964.) 128s. $6 d$.

$\mathrm{O}$ WING to their wide range of habitat and their poikilothermy, the Amphibia are a group of cardinal importance in the comparative physiology of the vertebrates. A second, and too often quite distinct, claim to fame is that some members of the group, the frog in particular, have provided generations of physiologists with convenient, readily available, preparations. It is to be hoped that Physiology of the Amphibia, with its clear indications of the many gaps in our present knowledge, will help to shift the emphasis from the latter role and accelerate progress toward an integrated physiology of these animals in relation to their varied environments.

The book is intended to be useful to both the amphibian and the general physiologist, and there can be no doubt that it performs a signal service for the former, for chapters on the digestive system (W. G. Reeder), blood and respiration (G. E. H. Foxon), water balance and kidney (I. J. Deyrup), and amphibian metabolism (G. W. Brown) may be instanced as providing lucid and effective syntheses of work which, with the possible exception of endocrine aspects of water balance, was sorely in need of collection and evaluation. For good measure, the book concludes with two chapters of a rather more specialized nature on developmental physiology (C. J. Barth) and regeneration (S. M. Rose). The general physiologist, on the other hand, will be primarily interested in this book because it makes work on the Amphibia more readily accessible, although there are two chapters ("Amphibian Muscle", B. C. Abbot and A. J. Brady; "The Amphibian Heart", A. J. Brady) which deal with fields where the frog has usually provided the experimental material without itself being the animal under investigation. Both contributions, which are heavily biased on the electrophysiological side, deal with work which is regularly reviewed at greater length than has been possible here, and it is therefore a pity that, apart from the slow fibre system in muscle, the opportunity has not been taken to include peculiarly amphibian aspects, such as seasonal phenomena.

The general editorial plan has not completely overcome the problems inherent in any attempt to produce a physiological treatise on a single group of animals. Several contributors feel that it is necessary to cover the whole range of their subject, at least in outline, even when nothing is derived from the Amphibia directly. This leads

\section{CROCIDURA}

\section{A Systematic Revision of the Shrew Genus Crocidura in Southern Africa}

By Jurgons Meester. (Memoir No. 13.) Pp. vii +127. (Pretoria: Transvaal Museum, 1963.) n.p.

HE shrews of the genus Crocidura, and of $1^{2}$ lated genora, constituto one of the most difficult taxonomic groups among the Mammalia. The difficulty lies mainly in the fact that the observable interspecific differences are so slight as to be obscured, if not equalled, by regional intraspecific variation. ('Observable' is the critical word-the shrews presumably recognize each other by scent, and if we could learn to do likewise many taxonomic problems would be resolved.) The taxonomist aiming to delimit the species is faced in reality with two tasks: first, tho detection of the essential characters, leading to the recognition of the species as biological entities; and secondly, the description of those specific characters that are of practical value for identification of the species.

The revision of a genus can only be regarded as definitive when it is considered simultaneously throughout its entire range. Such a task is premature at presont for Crocidura, ranging as it does from the Cape of Good Hope to Japan, but this volume, dealing with the southern part of Africa (south of the Zambesi), is a very valuable contribution towards that end. Nine species are recognized, and there are serious doubts about the validity of only one of them. The diagnoses, based almost entirely on size, colour of the pelage and dentition, inspire confidence in the validity of the results, but do not give a great deal of help to the non-taxonomist trying to identify species. A more detailed study of such external features as cars, nose, feet and scent-glands might have contributed some additional characters of practical as well as theoretical value. A valuable feature is the inclusion of distribution maps of each species, but the interpretation of the distribution is made unnecessarily devious by the attempt to correlate distribution primarily with rainfall and only secondarily with vegetation zones. The fact that the homoiothermic vertebrates are much more diroctly dependent on the biotic than the climatic component of their environment has been curiously overlooked by generations of biogeographers.

The introductory chapters contain a general account of the genus Crocidura and very detailed illustrated doseription of the skull and dentition of one species, $C$.flavescens. This should prove invaluable to the less experienced, or less specialized, taxonomist tackling other parts of this fascinating but frustrating group. $\quad$ C. B. CORBET 